\title{
Diffusion of hydrogen sulfide and methyl mercaptan onto microporous alkaline activated carbon
}

\author{
Hung-Lung Chiang ${ }^{\mathrm{a}, *}$, Jiun-Horng Tsai ${ }^{\mathrm{b}}$, Dai-Huang Chang ${ }^{\mathrm{b}}$, Fu-Teng Jeng ${ }^{\mathrm{c}}$ \\ a Department of Environmental Engineering, Fooyin Institute of Technology, Kaoshiung Hsien, Taiwan, ROC \\ ${ }^{\mathrm{b}}$ Graduate Institute of Environmental Engineering, National Cheng Kung University, Tainan, Taiwan, ROC \\ ${ }^{\mathrm{c}}$ Graduate Institute of Environmental Engineering, National Taiwan University, Taipei, Taiwan, ROC
}

Received 8 September 1999; accepted 17 November 1999

\begin{abstract}
Activated carbon kinetic studies show that both $\mathrm{H}_{2} \mathrm{~S}$ and $\mathrm{CH}_{3} \mathrm{SH}$ yielded pore diffusion coefficients from $10^{-6}$ to $10^{-8} \mathrm{~cm}^{2} / \mathrm{s}$. Results indicated that pore structures could influence effective diffusivity. Under the same adsorbate concentration, $\mathrm{CH}_{3} \mathrm{SH}$ exhibited a greater effective pore diffusion coefficient than $\mathrm{H}_{2} \mathrm{~S}$. This may be attributed to the fact that $\mathrm{CH}_{3} \mathrm{SH}$ has both polar $(-\mathrm{SH})$ and non-polar $\left(-\mathrm{CH}_{3}\right)$ functional groups and dissolves into water easier, thus providing more attraction for the activated carbon surface. In addition, the saturation vapor pressure of $\mathrm{CH}_{3} \mathrm{SH}$ is lower than that of $\mathrm{H}_{2} \mathrm{~S}$. Therefore, $\mathrm{CH}_{3} \mathrm{SH}$ is easier to adsorb onto activated carbon than $\mathrm{H}_{2} \mathrm{~S}$. (C) 2000 Elsevier Science Ltd. All rights reserved.
\end{abstract}

Keywords: Diffusivity; Hydrogen sulfide; Methyl mercaptan; Alkaline activated carbon

\section{Introduction}

Gaseous odors are emitted from various plants, such as sewage treatment plants and chemical industries (Vigneron et al., 1994). Odors from such plants are being treated by adsorption on activated carbon or impregnated activated carbon, scrubbing and neutralizing by chemical solution, condensation, mashing or catalytic combustion. Adsorption, however, is used most often to remove $\mathrm{H}_{2} \mathrm{~S}$ and $\mathrm{CH}_{3} \mathrm{SH}$ from gas streams (Turk et al., 1989; Koe and Tan, 1990). Therefore, several impregnated activated carbons have been developed for deodorization (Tsutsui and Tanada, 1987; Ikeda et al., 1988; Tsai et al., 1992, 1999).

When removing adsorbate from air mixtures flowing into granular activated carbon, the following sequence

\footnotetext{
${ }^{*}$ Corresponding author. Tel.: +1-886-7-782-8663; fax: +1886-7-782-9117.

E-mail address: hlchang@cc.fy.edu.tw (H.-L. Chiang).
}

of reaction steps is possible (Jonas, 1978): mass transfer, surface diffusion, intragranular diffusion, physical adsorption, gas desorption, chemical reaction and surface renewal. If the products of a chemical reaction are volatile and poorly adsorbed, they leave the macropore region and enter the fluid stream surrounding the carbon granule where they are swept away from the activated carbon by mass transport.

When Tien (1994) modified the results of Jonas, he noted that diffusion was the predominant mechanism in activated carbon sorption. Recent research on sorption by dry soil grains revealed that diffusion processes govern the rate at which gas-phase species reach the intragranular soil surface. The structural similarity between porous soil grains and activated carbon suggests similar mechanisms in both cases. Several related studies support this conclusion (Garg and Ruthven, 1972; Ruthven and Derrah, 1972; Gray and Do, 1989a,b, 1990).

The purpose of this study was to investigate the physicochemical characteristics of five activated 
carbons. External diffusion, macropore diffusion, and micropore diffusion of $\mathrm{H}_{2} \mathrm{~S}$ and $\mathrm{CH}_{3} \mathrm{SH}$ on the five activated carbons were calculated.

\section{Theory}

Three solid surface adsorption mechanisms were investigated: external diffusion and internal diffusion (macropore diffusion and micropore diffusion). These mechanisms affected the pore structural distribution of the adsorbent (Yang, 1987).

\subsection{External diffusion}

External diffusion is the gaseous reactant transfer from the bulk gas stream to the external surface of the solid particle. The mass flux being transferred from the gas stream to solid surface is given by Noll et al. (1992).

$N_{\mathrm{A}}=\frac{k_{\mathrm{f}} a_{\mathrm{p}} \varepsilon}{\rho_{\mathrm{p}}}\left(C-C_{\mathrm{s}}\right)$,

where $N_{\mathrm{A}}$ is the mass flux of the transferred species from gas stream to adsorbent surface, $k_{\mathrm{f}}$ the external film mass transfer coefficient, $a_{\mathrm{p}}$ the external surface area of adsorbent, $\varepsilon$ the voids between adsorbents, $\rho_{\mathrm{p}}$ the bulk density of adsorbent, $C$ the concentration of the transferred species in the bulk of gas stream, and $C_{\mathrm{s}}$ the concentration of the transferred species at the adsorbent surface.

For packed bed adsorption, the external film mass transfer coefficient $\left(k_{\mathrm{f}}\right)$ was correlated by the RanzMarshall equation following Eq. (2) (Noll et al., 1992):

$\mathrm{Sh}=\frac{2 k_{\mathrm{f}} r_{\mathrm{p}}}{D_{\mathrm{m}}}=2.0+0.6 \mathrm{Re}^{0.5} \mathrm{Sc}^{0.33}$,

where $D_{\mathrm{m}}$ is the molecular diffusivity, $r_{\mathrm{p}}$ the radius of adsorbent, Re the Reynolds number $\left(\operatorname{Re}=\left(2 r_{\mathrm{p}} V_{\mathrm{s}} \rho_{\mathrm{f}} / \mu\right)\right)$, Sc the Schmidt number $\left(\mathrm{Sc}=\mu /\left(D_{\mathrm{m}} \rho_{\mathrm{f}}\right)\right)$, Sh the Sherwood number $\left(\mathrm{Sh}=\left(2 k_{\mathrm{f}} r_{\mathrm{p}}\right) / D_{\mathrm{m}}\right), \mu$ the viscosity of gas stream, $V_{\mathrm{s}}$ the velocity of gas stream, and $\rho_{\mathrm{f}}$ is the density of gas stream.

\subsection{Internal diffusion}

\subsubsection{Macropore diffusion}

The importance of heterogeneous catalysis in macropore diffusion has been a popular research subject. There are four kinds of macropore diffusion: (1) molecular diffusion, (2) Knudsen diffusion, (3) Poiseuille flow diffusion, and (4) surface diffusion. The diffusion mechanisms have been shown to affect adsorbent pore structure distribution (Ruthven, 1984).

The mathematical relationships for each macropore diffusion are shown below:

\section{(1) Molecular diffusion:}

$D_{\mathrm{p}}=\frac{D_{\mathrm{m}}}{\tau}$,

where $D_{\mathrm{p}}$ is the pore diffusivity, $D_{\mathrm{m}}$ the molecular diffusivity and $\tau$ is the tortousity factor.

Fuller et al. derived the molecular diffusivity $\left(D_{\mathrm{m}}\right)$ of a two-component system as follows (Bird et al., 1960; Sherwood et al., 1975; Hines and Maddox, 1985; Szekely et al., 1976):

$D_{\mathrm{m}}=\frac{1.0 \times 10^{-3} \times T^{1.75}}{P\left[\left(\sum v\right)_{\mathrm{A}}^{1 / 3}+\left(\sum v\right)_{\mathrm{B}}^{1 / 3}\right]^{2}}\left(\frac{1}{M_{\mathrm{A}}}+\frac{1}{M_{\mathrm{B}}}\right)^{1 / 2}$,

where $P$ is the pressure of gas stream, $T$ the absolute temperature, $\left(\sum v\right)_{\mathrm{A}}$ and $\left(\sum v\right)_{\mathrm{B}}$ are the molecular volumes of gases $\mathrm{A}$ and $\mathrm{B}$, and $M_{\mathrm{A}}$ and $M_{\mathrm{B}}$ are the gas molecular weights of A and B. Generally, the mean free path of molecules is smaller than the pore diameter of the adsorbent. The transport mechanism is therefore molecular diffusion.

(2) Knudsen diffusion: Knudsen showed that under these conditions the diffusivity per unit cross-sectional area of pore is given by

$D_{\mathrm{k}}=\frac{2}{3} r \bar{v}=9700 r_{\mathrm{p}} \sqrt{\frac{T}{M}}$

where $D_{\mathrm{k}}, r_{\mathrm{p}}, \bar{v}, T$ and $M$ are Knudsen diffusivity, pore radius, mean molecular velocity, absolute temperature and molecular weight, respectively.

(3) Surface diffusion: The overall diffusion coefficient is shown as:

$D=D_{\mathrm{k}}+\left(\frac{1-\varepsilon_{\mathrm{p}}}{\varepsilon_{\mathrm{p}}}\right) \cdot K D_{\mathrm{s}}$,

where $D$ is the overall diffusivity, $D_{\mathrm{k}}$ the Knudsen diffusivity, $\varepsilon_{\mathrm{p}}$ the adsorbent porosity, $K$ the equilibrium constant, and $D_{\mathrm{s}}$ is the surface diffusivity.

\subsubsection{Micropore diffusion}

According to Fick's law, one has

$N=-D \frac{\partial C}{\partial r}$,

where $N$ is the mass flux of transferred species, $D$ the effective diffusivity of transferred species, $C$ the concentration of transferred species, and $r$ is the distance normal to the external surface.

The micropore diffusion is derived as follows (Noll et al., 1992):

$\frac{\partial q}{\partial t}=\frac{1}{r^{2}} \frac{\partial}{\partial r}\left(r^{2} D_{\mathrm{c}} \frac{\partial q}{\partial r}\right)$ 
Assuming $D_{\mathrm{c}}$ is constant, Eq. (8) can be derived as Eq. (9).

$\frac{\partial q}{\partial t}=D_{\mathrm{c}}\left(\frac{\partial^{2} q}{\partial r^{2}}+\frac{2}{r} \frac{\partial q}{\partial r}\right)$

The initial and boundary condition are shown as follows:

$q(r, 0)=q_{0}, \quad q\left(r_{\mathrm{c}}, t\right)=q_{0}, \quad\left(\frac{\partial q}{\partial r}\right)_{r=0}=0$,

then

$\frac{\bar{q}-q_{0}}{q_{0}-q_{0}}=\frac{M_{t}}{M_{\infty}}=1-\frac{6}{\pi^{2}} \sum_{n=1}^{\infty} \frac{1}{n^{2}} \exp \left(-\frac{n^{2} \pi^{2} D_{\mathrm{c}} t}{r_{\mathrm{c}}^{2}}\right)$

and

$\bar{q}=\frac{3}{r_{\mathrm{c}}^{3}} \int_{0}^{r_{\mathrm{c}}} q \cdot r^{2} \mathrm{~d} r$

where $q$ is the amount adsorbed (per unit volume of sorbent), $\bar{q}$ the average amount adsorbed in a pellet or particle, $M_{\infty}$ the total mass uptake at a gas-phase concentration of $C_{0}$ and $M_{\theta}$ is the cumulative mass uptake at dimensionless time $\theta$.

\section{Experimental}

This research selected spent activated carbon (SAC), regenerative activated carbon (RAC), fresh activated carbon (FAC), impregnated-regenerative activated carbon (RAC-N), and impregnated-fresh activated carbon (FAC-N) as the experimental adsorbents. The activated carbons were made from coconut shell.

\subsection{Regeneration of spent activated carbon}

$50 \mathrm{~g}$ of SAC (Chinese Carbon, Taiwan) was placed into a vacuum oven $\left(10^{-1}-10^{-2} \mathrm{mmHg}\right)$ at room temperature, under nitrogen $(99.95 \%)$, for $2 \mathrm{~h}$. Next, $10 \mathrm{~g}$ of the pretreated SAC was put into an oven at $400^{\circ} \mathrm{C}$ for $1.5 \mathrm{~h}$. The high purity nitrogen gas was used to cool the oven. The regenerative-spent activated carbon was stored in gas-sealed vials until experimentation.

\subsection{Preparation of impregnated activated carbons}

$50 \mathrm{~g}$ of activated carbon (RAC or FAC) was placed into an oven and dried with flowing nitrogen gas $\left(140^{\circ} \mathrm{C}\right)$ for $6 \mathrm{~h}$. The pretreated activated carbons were immersed in $500 \mathrm{ml}^{-1} \mathrm{~N} \mathrm{NaOH}$ solution (Merck, Germany) and stirred for $30 \mathrm{~min}$. The immersed activated carbons were kept in a vacuum oven for $30 \mathrm{~min}$ and in a dryer (glass container with silica gel) for $200 \mathrm{~min}$ (stationary times) at room temperature. The immersed activated carbons were then filtered from the impregnation solutions and dried in an oven at $130^{\circ} \mathrm{C}$ for $60 \mathrm{~h}$. The prepared alkaline activated carbons were stored in gas tight, nitrogen gas-filled containers before use.

\subsection{Physical characteristics}

The activated carbons were stored in an oven at $105^{\circ} \mathrm{C}$ and dried for $48 \mathrm{~h}$. The physical characteristics of the activated carbon, including specific surface area, micropore area, total pore volume, micropore volume and pore diameter were measured with $N_{2}(g)$ adsorption using an ASAP 2000 Micropore Analyzer (Micromeritrics, USA) at $77 \mathrm{~K}$ using liquid $\mathrm{N}_{2}$.

\subsection{Amount of alkaline on activated carbon}

The quantity of alkaline or $\mathrm{NaOH}$ on each activated carbon was determined by extraction and titration processes. The impregnated activated carbons were placed in a vacuum oven $\left(1-10^{-1} \mathrm{~mm} \mathrm{Hg}, 105^{\circ} \mathrm{C}\right)$ for 24 h. $\mathrm{HCl}$ solution $(1 \mathrm{~N})$ was then added, and the mixture stored at $25^{\circ} \mathrm{C}$ for $24 \mathrm{~h}$. To separate the supernatant, the sample was centrifuged at $3000 \mathrm{rpm}$ for ten min. The supernatant was then titrated with $1 \mathrm{~N} \mathrm{NaOH}$ solution until $\mathrm{pH} 7$.

\subsection{Sorption experiment}

A simulated blend of cylinder gases was passed through a glass column $20 \mathrm{~cm}$ in length and $28 \mathrm{~mm}$ in diameter. The bottom of the adsorption column was packed with a layer of $10-\mathrm{cm}$ glass beads. $5-10 \mathrm{~g}$ of activated carbon (radius $0.5 \mathrm{~mm}$ ) was packed in the column for each run. Cylinder gases of $\mathrm{H}_{2} \mathrm{~S}(8000 \mathrm{ppm})$ and $\mathrm{CH}_{3} \mathrm{SH}(99.9 \%)$ were certified by suppliers (Scott Gas Company, USA). The influent concentrations of $\mathrm{H}_{2} \mathrm{~S}$ and $\mathrm{CH}_{3} \mathrm{SH}$ ranged from 30-200 ppmv in the adsorption system. The flow rate, which ranged from 2.0$10 \mathrm{l} / \mathrm{min}$, was controlled by a mass flow meter (Sierra Series 9000, USA).

$\mathrm{H}_{2} \mathrm{~S}$ and $\mathrm{CH}_{3} \mathrm{SH}$ stream constituents were analyzed by a Gas Chromatograph (HP-6890) equipped with a Pulsed Flame Photometric Detector (PFPD) and chromatographic column (G.S.Q.: $30 \mathrm{~m}, \varnothing: 0.53 \mathrm{~mm}$ ). Temperature of injector, column, and detector were 180 , 150 , and $220^{\circ} \mathrm{C}$, respectively. Retention times of $\mathrm{H}_{2} \mathrm{~S}$ and $\mathrm{CH}_{3} \mathrm{SH}$ were 4.1 and $5.93 \mathrm{~min}$, respectively. The adsorption capacities of $\mathrm{H}_{2} \mathrm{~S}$ and $\mathrm{CH}_{3} \mathrm{SH}$ on each activated carbon in the gas stream were analyzed by the $\mathrm{GCl}$ PFPD and calculated by column adsorption kinetic curves. Quality control was also conducted to ensure experimental data performance. 


\section{Results and discussion}

\subsection{Physico-chemical characteristics of activated carbons}

Physico-chemical characteristics of the five activated carbons are shown as Table 1. The sequence of BET surface area, micropore area, pore volume and micropore volume were as follows: FAC $>$ FAC-N $>$ RAC $>$ RAC-N $>$ SAC. The pore diameter distribution was $\mathrm{SAC}>\mathrm{RAC}>\mathrm{RAC}-\mathrm{N}>\mathrm{FAC} \approx \mathrm{FAC}-\mathrm{N}$. The amount of alkaline equivalent on the activated carbons was FAC-N $>$ RAC-N $>$ FAC $>$ RAC $>$ SAC. Results indicated that SAC was the least effective adsorbent of the five activated carbons. $\mathrm{NaOH}$ impregnation changed their physicochemical characteristics.

\subsection{External diffusion}

At $298 \mathrm{~K}$, the viscosity of air, $\mathrm{H}_{2} \mathrm{~S}, \mathrm{CH}_{3} \mathrm{SH}$, air- $\mathrm{H}_{2} \mathrm{~S}$ gas mixture and air- $\mathrm{CH}_{3} \mathrm{SH}$ gas mixture are 184.6, $126.5,95.8,170.5$ and $143.5 \mu \mathrm{P}$, respectively. The Reynolds number, Schmidt number and Sherwood number were $16.1,1.1$, and 8.0 for the $\mathrm{H}_{2} \mathrm{~S}$-air mixture system, and $12.0,2.0$ and 8.1 for the $\mathrm{CH}_{3} \mathrm{SH}$-air mixture system. The external film mass transfer $\mathrm{H}_{2} \mathrm{~S}$ and $\mathrm{CH}_{3} \mathrm{SH}$ coefficients were 14.8 and $11.2 \mathrm{~cm} / \mathrm{s}$, respectively.

\subsection{Macropore diffusion}

The diffusion of adsorbates in macropore-molecular diffusion, surface diffusion, and Knudsen diffusion, were considered the diffusion mechanisms. Results of the $\mathrm{H}_{2} \mathrm{~S}$ and $\mathrm{CH}_{3} \mathrm{SH}$ macropore diffusivity into the five activated carbons (SAC, FAC, RAC, RAC-N, and FAC-N) are shown in Table 2.

\subsubsection{Molecular diffusion}

According to Eq. (4), molecular diffusivity affects the temperature, pressure, molecular weight and adsorbate characteristics. In this research, the molecular diffusivity of the Air- $\mathrm{H}_{2} \mathrm{~S}$ and Air- $\mathrm{CH}_{3} \mathrm{SH}$ systems were 0.185 and $0.138 \mathrm{~cm}^{2} / \mathrm{s}$, respectively. The molecular weight and volume of $\mathrm{H}_{2} \mathrm{~S}$ is smaller than $\mathrm{CH}_{3} \mathrm{SH}$, so the molecular diffusivity of $\mathrm{H}_{2} \mathrm{~S}$ was greater than $\mathrm{CH}_{3} \mathrm{SH}$.

\subsubsection{Knudsen diffusion}

When the mean free path of the adsorbate is greater than the pore diameter of the activated carbon, the collision of molecules and the pore wall can inhibit molecule transport. The Knudsen diffusivity is a function of the pore radius, temperature and molecular weight (Eq. (5)). Analysis indicated that the Knudsen diffusivity of $\mathrm{H}_{2} \mathrm{~S}$ was between $4.33 \times 10^{-3}$ and $5.04 \times 10^{-3} \mathrm{~cm}^{2} / \mathrm{s}$ and that of $\mathrm{CH}_{3} \mathrm{SH}$ was between $3.51 \times 10^{-3}$ and $4.24 \times 10^{-3} \mathrm{~cm}^{2} / \mathrm{s}$. The Knudsen diffusivity was directly proportional to the pore radius under identical adsorbate and adsorption temperature conditions. Since $\mathrm{CH}_{3} \mathrm{SH}$ molecular weight is greater than $\mathrm{H}_{2} \mathrm{~S}$, the Knudsen diffusivity of $\mathrm{H}_{2} \mathrm{~S}$ was greater than $\mathrm{CH}_{3} \mathrm{SH}$ in an adsorption system.

\subsubsection{Diffusion of transient region}

The diffusivity of the transient region can be calculated as

Table 1

Physico-chemical characteristics of activated carbons

\begin{tabular}{lclllll}
\hline Adsorbents & $\begin{array}{l}\text { BET surface } \\
\text { area }\left(\mathrm{m}^{2} / \mathrm{g}\right)\end{array}$ & $\begin{array}{l}\text { Micropore } \\
\text { area }\left(\mathrm{m}^{2} / \mathrm{g}\right)\end{array}$ & $\begin{array}{l}\text { Pore volume } \\
\left(\mathrm{cm}^{3} / \mathrm{g}\right)\end{array}$ & $\begin{array}{l}\text { Micropore } \\
\text { volume }\left(\mathrm{cm}^{3} / \mathrm{g}\right)\end{array}$ & $\begin{array}{l}\text { Pore } \\
\text { diameter }(\AA)\end{array}$ & $\begin{array}{l}\text { Alkaline } \\
\text { equivalent }(\mathrm{meq} / \mathrm{g})\end{array}$ \\
\hline SAC & 285 & 186 & 0.170 & 0.088 & 17.6 & 0.75 \\
RAC & 794 & 610 & 0.429 & 0.282 & 16.1 & 1.75 \\
FAC & 1282 & 864 & 0.623 & 0.394 & 14.6 & 1.88 \\
RAC-N & 664 & 505 & 0.338 & 0.238 & 15.1 & 2.63 \\
FAC-N & 1188 & 789 & 0.581 & 0.335 & 14.5 & 3.13 \\
\hline
\end{tabular}

Table 2

Macropore diffusion of $\mathrm{H}_{2} \mathrm{~S}$ and $\mathrm{CH}_{3} \mathrm{SH}$ on activated carbons

\begin{tabular}{|c|c|c|c|c|}
\hline \multirow[t]{2}{*}{ Adsorbents } & \multicolumn{2}{|c|}{$\mathrm{H}_{2} \mathrm{~S}\left(\mathrm{~cm}^{2} / \mathrm{s}\right)$} & \multicolumn{2}{|c|}{$\mathrm{CH}_{3} \mathrm{SH}\left(\mathrm{cm}^{2} / \mathrm{s}\right)$} \\
\hline & $D_{\mathrm{k}} \times 10^{3}$ & $D \times 10^{3}$ & $D_{\mathrm{k}} \times 10^{3}$ & $D \times 10^{3}$ \\
\hline SAC & 4.33 & 4.23 & 3.64 & 3.55 \\
\hline RAC & 4.63 & 4.52 & 3.90 & 3.79 \\
\hline FAC & 4.19 & 4.09 & 3.52 & 3.44 \\
\hline RAC-N & 5.04 & 4.91 & 4.24 & 4.11 \\
\hline FAC-N & 4.18 & 4.08 & 3.51 & 3.43 \\
\hline
\end{tabular}


$\frac{1}{D}=\frac{1}{D_{\mathrm{k}}}+\frac{1}{D_{\mathrm{m}}}\left[1-\left(1+\frac{N_{\mathrm{B}}}{N_{\mathrm{A}}}\right) X_{\mathrm{A}}\right]$

where $D$ is diffusivity of the transient region, $N_{\mathrm{A}}$ and $N_{\mathrm{B}}$ are the molecular transport flux of $A$ and $B$, and $X_{\mathrm{A}}$ is the molar fraction of $A$. Assuming the molecular transport flux of $A$ is equal to that of $B\left(N_{\mathrm{A}}=N_{\mathrm{B}}\right)$, the equation simplifies to

$\frac{1}{D}=\frac{1}{D_{\mathrm{k}}}+\frac{1}{D_{\mathrm{m}}}$

The diffusivity of $\mathrm{H}_{2} \mathrm{~S}$ was between $4.08 \times 10^{-3}$ and $4.91 \times 10^{-3} \mathrm{~cm}^{2} / \mathrm{s}$ and that of $\mathrm{CH}_{3} \mathrm{SH}$ was between $3.43 \times 10^{-3}$ and $4.11 \times 10^{-3} \mathrm{~cm}^{2} / \mathrm{s}$ in the transient region.

\subsection{Micropore diffusion}

Governing model equations with similar boundary and initial conditions have been solved by several investigators. In this research, a numeric method and Fortran least squares program were used to solve the governing equation.

The adsorption diffusivity of $\mathrm{H}_{2} \mathrm{~S}$ and $\mathrm{CH}_{3} \mathrm{SH}$ on the five activated carbons are shown as Table 3 .

\subsubsection{Effective diffusivity of $\mathrm{H}_{2} \mathrm{~S}$ adsorbed on activated carbon}

The effective diffusivity of $\mathrm{H}_{2} \mathrm{~S}$ that was adsorbed on activated carbon was between $2.1 \times 10^{-8}$ and $6.49 \times 10^{-6} \mathrm{~cm}^{2} / \mathrm{s}$. When the influent concentration of $\mathrm{H}_{2} \mathrm{~S}$ was increased from 50 to 100 ppmv, the effective diffusivity increased: SAC from $5.35 \times 10^{-6}$ to $6.49 \times 10^{-6} \mathrm{~cm}^{2} / \mathrm{s}$, RAC from $1.02 \times 10^{-7}$ to $1.19 \times 10^{-7}$ $\mathrm{cm}^{2} / \mathrm{s}$, FAC from $7.3 \times 10^{-8}$ to $8.8 \times 10^{-8} \mathrm{~cm}^{2} / \mathrm{s}$, RAC$\mathrm{N}$ from $2.1 \times 10^{-8}$ to $2.7 \times 10^{-8} \mathrm{~cm}^{2} / \mathrm{s}$, and FAC-N from $2.1 \times 10^{-8}$ to $4.0 \times 10^{-8} \mathrm{~cm}^{2} / \mathrm{s}$.

\subsubsection{Effective diffusivity of $\mathrm{CH}_{3} \mathrm{SH}$ adsorbed on activat- ed carbon}

When the influent concentration of $\mathrm{CH}_{3} \mathrm{SH}$ was increased from 50 to $100 \mathrm{ppm}$, the effective diffusivity increased: SAC from $5.02 \times 10^{-6}$ to $5.78 \times 10^{-6} \mathrm{~cm}^{2} / \mathrm{s}$, RAC from $1.36 \times 10^{-7}$ to $1.42 \times 10^{-7} \mathrm{~cm}^{2} / \mathrm{s}$, FAC from
$3.21 \times 10^{-7}$ to $3.95 \times 10^{-7} \mathrm{~cm}^{2} / \mathrm{s}$, RAC-N from $7.2 \times 10^{-8}$ to $8.7 \times 10^{-8} \mathrm{~cm}^{2} / \mathrm{s}$, and FAC-N from $1.03 \times 10^{-7}$ to $1.27 \times 10^{-7} \mathrm{~cm}^{2} / \mathrm{s}$.

Results indicated that the larger the pore diameter, the larger the effective diffusivity and the higher the influent concentration, the higher the effective diffusivity.

The effective diffusivity of $\mathrm{H}_{2} \mathrm{~S}$ and $\mathrm{CH}_{3} \mathrm{SH}$ on RAC$\mathrm{N}$ from 30 to 200 ppmv is shown as Fig. 1.

When the influent concentration of $\mathrm{H}_{2} \mathrm{~S}$ was increased from 30 to 200 ppmv, the effective diffusivity of $\mathrm{H}_{2} \mathrm{~S}$ adsorbed on RAC-N increased from $1.63 \times 10^{-8}$ to $3.89 \times 10^{-8} \mathrm{~cm}^{2} / \mathrm{s}$. When the influent concentration of $\mathrm{CH}_{3} \mathrm{SH}$ was increased from 30 to $200 \mathrm{ppmv}$, the effective diffusivity of $\mathrm{CH}_{3} \mathrm{SH}$ adsorbed on RAC-N ranged from $5.31 \times 10^{-8}$ to $1.03 \times 10^{-7} \mathrm{~cm}^{2} / \mathrm{s}$.

Given the same influent concentrations of $\mathrm{H}_{2} \mathrm{~S}$ and $\mathrm{CH}_{3} \mathrm{SH}$, the effective diffusivity of $\mathrm{CH}_{3} \mathrm{SH}$ was greater than that of $\mathrm{H}_{2} \mathrm{~S}$. This can be attributed to methyl mercaptan having both a polar functional group $(\mathrm{S}-\mathrm{H})$ and a non-polar functional group $(\mathrm{C}-\mathrm{H})$. Methyl mercaptan tends to be adsorbed more easily on activated carbon than $\mathrm{H}_{2} \mathrm{~S}$. Additionally, a high concentration of adsorbate in the micropores of the activated carbon may increase the van der Waal's force (due to condensation). The saturation vapor pressure is $19.807 \mathrm{~atm}$ for $\mathrm{H}_{2} \mathrm{~S}$ and

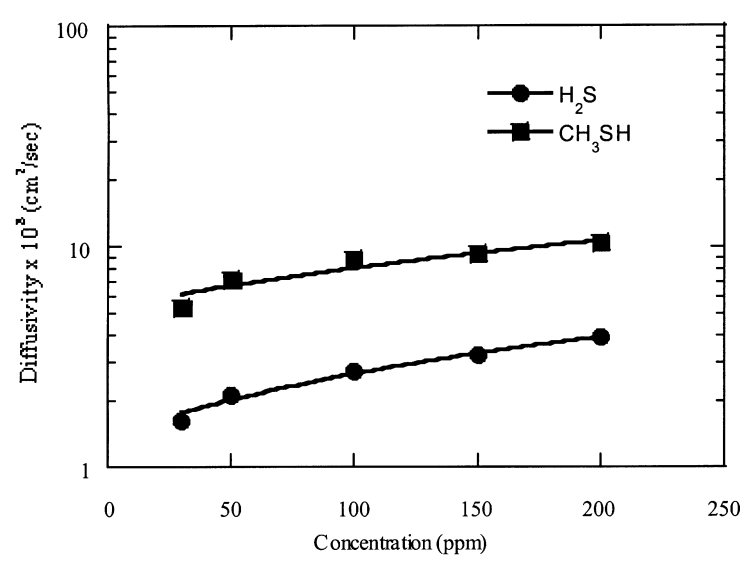

Fig. 1. Effective diffusivity of $\mathrm{H}_{2} \mathrm{~S}$ and $\mathrm{CH}_{3} \mathrm{SH}$ onto RAC-N. The adsorption temperature was controlled at $25^{\circ} \mathrm{C}$.

Table 3

Effective diffusivity of $\mathrm{H}_{2} \mathrm{~S}$ and $\mathrm{CH}_{3} \mathrm{SH}$ on activated carbons

\begin{tabular}{llllll}
\hline \multirow{2}{*}{ Adsorbents } & $\mathrm{H}_{2} \mathrm{~S}\left(\mathrm{~cm}^{2} / \mathrm{s}\right)$ & & \multicolumn{2}{c}{$\mathrm{CH}_{3} \mathrm{SH}\left(\mathrm{cm}^{2} / \mathrm{s}\right)$} & \\
\cline { 2 - 3 } \cline { 5 - 6 } & $50 \mathrm{ppmv}$ & & & $50 \mathrm{ppmv}$ & $100 \mathrm{ppmv}$ \\
\hline SAC & $5.35 \times 10^{-6}(0.96)^{\mathrm{a}}$ & $6.49 \times 10^{-6}(0.97)$ & & $5.02 \times 10^{-6}(0.90)$ & $5.78 \times 10^{-6}(0.91)$ \\
RAC & $1.02 \times 10^{-7}(0.91)$ & $1.19 \times 10^{-7}(0.99)$ & & $1.36 \times 10^{-7}(0.92)$ & $1.42 \times 10^{-7}(0.90)$ \\
FAC & $2.1 \times 10^{-8}(0.92)$ & $8.8 \times 10^{-8}(0.97)$ & & $3.21 \times 10^{-7}(0.92)$ & $3.95 \times 10^{-7}(0.92)$ \\
RAC-N & $2.7 \times 10^{-8}(0.89)$ & $2.7 \times 10^{-8}(0.94)$ & & $7.20 \times 10^{-8}(0.91)$ & $8.7 \times 10^{-8}(0.92)$ \\
FAC-N & $2.1 \times 10^{-8}(0.92)$ & $4.0 \times 10^{-8}(0.94)$ & & $1.03 \times 10^{-7}(0.92)$ & $1.27 \times 10^{-8}(0.91)$ \\
\hline
\end{tabular}

\footnotetext{
${ }^{a}$ Regression coefficient of adsorption curve (experiments) and fitting curve (diffusion model).
} 
is $1.943 \mathrm{~atm}$ for $\mathrm{CH}_{3} \mathrm{SH}$ at $25^{\circ} \mathrm{C}$ (Reid et al., 1988). These values indicate that the $\mathrm{CH}_{3} \mathrm{SH}$ is more easily condensed in the micropores of activated carbon. Therefore, the effective diffusivity of $\mathrm{CH}_{3} \mathrm{SH}$ is larger than that of $\mathrm{H}_{2} \mathrm{~S}$.

\section{Conclusions}

Influent concentrations of $\mathrm{H}_{2} \mathrm{~S}$ and $\mathrm{CH}_{3} \mathrm{SH}$ were 30 to $200 \mathrm{ppmv}$, the effective diffusion coefficients were $10^{-8}$ to $10^{-6} \mathrm{~cm}^{2} / \mathrm{s}$. $\mathrm{CH}_{3} \mathrm{SH}$ exhibited an effective pore diffusion coefficient greater than that of $\mathrm{H}_{2} \mathrm{~S}$ at the same adsorbate concentration. This may be attributed to the fact that $\mathrm{CH}_{3} \mathrm{SH}$ has both polar $(-\mathrm{SH})$ and non-polar $\left(-\mathrm{CH}_{3}\right)$ functional groups with a strong affinity toward the activated carbon surface. Furthermore, the saturation vapor pressure of $\mathrm{CH}_{3} \mathrm{SH}(1.943 \mathrm{~atm})$ is lower than that of $\mathrm{H}_{2} \mathrm{~S}(19.807 \mathrm{~atm})$ at $298 \mathrm{~K}$. This indicates that $\mathrm{CH}_{3} \mathrm{SH}$ is easier to condense in micropore carbon than $\mathrm{H}_{2} \mathrm{~S}$. Results indicate that influent concentration and pore structure can affect the effective diffusivity.

\section{Acknowledgements}

The authors express their sincere thanks to the National Science Council, Taiwan, ROC for its support (NSC 87-2211-E-006-004 and NSC-88-2211-E-006-009) of this study.

\section{References}

Bird, R.B., Stewart, W.E., Lightfoot, E.N., 1960. Transport Phenomena. Wiley, New York.

Garg, D.R., Ruthven, D.M., 1972. The effect of the concentration dependence of diffusivity on zeolite sorption curves. Chem. Eng. Sci. 27, 95-99.

Gray P.G, Do, D.D., 1989a. Adsorption and desorption of gaseous sorbates on a bidispered particle with freundilch isotherm: I. theory analysis. Gas Sep. Purif. 3, 193-200.

Gray, P.G., Do, D.D., 1989b. Adsorption and desorption of gaseous sorbates on a bidispered particle with freundilch isotherm: II experimental study of sulphur dioxide sorption on activated carbon particles. Gas Sep. Purif. 3, 201-208.
Gray, P.G., Do, D.D., 1990. Adsorption and desorption dynamics of sulphur dioxide on a single large activated carbon particles. Chem. Eng. Comm. 96, 141-154.

Hines, A.L., Maddox, R.N., 1985. Mass Transfer: Fundamentals and Application. Prentice-Hall, New Jersey.

Ikeda, H., Asaba, H., Takeuchi, Y., 1988. Removal of $\mathrm{H}_{2} \mathrm{~S}$, $\mathrm{CH}_{3} \mathrm{SH}$ and $\left(\mathrm{CH}_{3}\right)_{3} \mathrm{~N}$ from air by use of chemically treated activated carbon. J. Chem. Eng. Jpn. 21, 91-97.

Jonas, L.A., 1978. Reaction steps in gas sorption by impregnated carbon. Carbon 16, 115-119.

Koe, L.C.C., Tan, N.C., 1990. Comparison of field and laboratory $\mathrm{H}_{2} \mathrm{~S}$ adsorption capacity of activated carbon. Water Air Soil Pollut. 50, 969-976.

Noll, K.E., Gounaris, V., Hou, W.S., 1992. Adsorption Technology for Air and Water Pollution Control. Lewis Publishers, Michigan.

Reid, R.C., Prausnite, J.M., Poling, B.E., 1988. The Properties of Gases and Liquids, fourth ed., McGraw-Hill, New York.

Ruthven, D.M., 1984. Principles of Adsorption \& Adsorption Process. Wiley, New York.

Ruthven, D.M., Derrah, R.I., 1972. Sorption in davison 5a molecular sieves. Can. J. Chem. Eng. 50, 743-747.

Sherwood, T.K., Pigford, R.L., Wikle, C.R., 1975. Mass Transfer. McGRAW-Hill, New York.

Szekely, J., Evans, J.W., Sohn, H.Y., 1976. Gas-Solid Reactions. Academic Press, New York.

Tien, C., 1994. Adsorption Calculations and Modeling. Butterworth-Heineman, Maryland.

Tsai, J.H., Chiang, H.L., Tsai, C.L., Hsu, Y.C., 1999. Adsorption of hydrogen sulfide and methyl mercaptan mixture gas on alkaline activated carbon. J. Chin. Inst. Environ. Eng., in press.

Tsai, J.H., Jeng, F.T., Yen, S.H., 1992. Treatment of $\mathrm{NH}_{3}$ and $\mathrm{H}_{2} \mathrm{~S}$ mixture gas by sorption. J. Chin. Inst. Environ. Eng. 22, 211-218.

Tsutsui, S., Tanada, S., 1987. Adsorption of hydrogen sulfide, dimethyl sulfide and their binary mixture into pores of $n$ containing activated carbon. Chem. Pharm. Bull. 35, 12381242.

Turk, A., Sakalis, E., Lessuck, J., Karamitsos, H., Rago, O., 1989. Ammonia injection enhances capacity of activated carbon for hydrogen sulfide and methyl mercaptan. Environ. Sci. Technol. 23, 1242-1245.

Vigneron, S., Hermia, J., Chaouki, J., 1994. Characterization and Control of Odours and VOC in the Processes Industries. Elsevier, Amsterdam.

Yang, R.T., 1987. Gas Seperation by Adsorption Processes. Butterworth, Boston. 